Journal of Engineering and Applied Sciences 15 (4): 1007-1013, 2020

ISSN: 1816-949X

(C) Medwell Journals, 2020

\title{
Resonance Method for Determining Moisture of Cohesive Soils at the Plastic Limit
}

\author{
${ }^{1}$ Philippe Daniel, ${ }^{2}$ Victor Yavna, ${ }^{2}$ Sergey Sulavko, \\ ${ }^{2}$ Zelimkhan Khakiev and ${ }^{2}$ Andrei Kochur \\ ${ }^{1}$ Université du Maine, Avenue Olivier Messiaen, 72085 Le Mans, France \\ ${ }^{2}$ Rostov State Transport University, 2 Narodnogo Opolcheniya Sqr., \\ 344038 Rostov-on-Don, Russia
}

\begin{abstract}
For bentonite clays and kaolin, the studies were carried out to establish a correlation between the moisture at the plastic limit determined by traditional laboratory methods and the complex permittivity determined by the method of resonance measurements in the microwave range of electromagnetic waves at frequencies of 1.4-1.7 GHz. The effect of crystallization of water located between clay particles on the clays electrophysical properties is studied.
\end{abstract}

Key words: Resonance method, plastic limit, bentonite clays, soils moisture, kaolinite, plasticity

\section{INTRODUCTION}

Currently, the construction of artificial structures for civil and transport purposes is carried out at an intensive pace in various engineering and geological conditions around the world. The durability and strength of soil structures depends on the quality of engineering projects and construction technologies, they in turn, depend on the accuracy of determining the characteristics of soil materials localized along the objects under construction. These circumstances explain the conduct of studies aimed at increasing the accuracy of methods for determining the mechanical properties of soils. One of the most important mechanical properties that determine the possibility of using soil as a building material is plasticity.

This property of cohesive soils is determined by the features of the hydration of minerals that form clay particles. Despite the large number of works devoted to this problem, there is no generally accepted point of view in understanding the mechanisms of interaction of layered aluminum silicates with substances in liquid-phase reactions in the definition of a "bound water" and in determining the plasticity and sorption properties of these objects (Bergaya et al., 2006).

In this regard, a detailed study of hydration processes by modern physical methods is of high theoretical and practical interest. As a rule, respective theoretical studies are carried out using the Density Functional Theory (DFT) method which has proven itself in calculating the structural and vibrational characteristics, sorption, electrical, mechanical and other physical properties of these objects (Ortega-Castro et al., 2009; Scholtzova et al., 2013; He etal., 2013; Timon et al.,
2013; Wungu et al., 2012). Recent studies have made it possible to clarify the nature of the interaction of the $\mathrm{H}_{2} \mathrm{O}$ molecules with the adsorbing surfaces of soil-forming minerals and structural changes in the interacting atomic groups during this process (Zhang et al., 2014; Solc et al., 2011; Hu and Michaelides, 2007; Liu et al., 2012).

In engineering-geological studies, the plasticity of soils is determined by their moistures during the transition of soils from solid to plastic state and from plastic to liquid state. The first moisture value is denoted by $\mathrm{W}_{\mathrm{P}}$ and is determined according to the GOST 5180-2015 (2016). This value is equivalent to the parameter PL (Plastic Limit), determined according to ISO/TS 17892-12(2004) or ASTM D-4318-10 (2010). In the same manner, the moisture at the liquid limit $\mathrm{W}_{\mathrm{L}}$ is determined according to GOST 5180-2015 (2016) while the equivalent LL value is determined according to ISO/TS 17892-12 (2004) and ASTMD-4318 (2010). The moisture interval between the plastic and liquid limits determines the plasticity index Ip GOST 5180-2015, 2015) or IP ASTM D-4318 (2010); it is used as a parameter in soil classification. Plasticity is an individual property of clay-water systems and is determined by the mineral composition, particle size distribution, admixture of organic substances and other additives that can affect the properties of clays (Andrade et al., 2011).

Methods for measuring the characteristics of clay soils that determine plasticity are not accurate and reliable. They are based on subjective qualitative information and depend on the technical skills of the personnel conducting the measurements (Modesto and Bernardin, 2008; Kasprzhitskii et al., 2018). It was noted by Zornberg et al. (2008) that these traditional methods 
do not reproduce properly the operating conditions of structures made of low-quality soil materials and require an excessively long time for testing.

This study proposes an alternative method that involves infiltrating water into highly plastic clays in a centrifuge. By Modesto and Bernardin (2008), Kasprzhitskii et al. (2018), Vlcek et al. (2016), Kodicherla and Nandyala (2016) and Waruru et al. (2014), the results of studies aimed at developing methods that are rapid and have increased accuracy of the results are analyzed. For this purpose, Andrade et al. (2011), Modesto and Bernardin (2008), Kodicherla and Nandyala (2016) and Verma and Maru (2013), the methods of mechanical action on the soil were used. By Kasprzhitskii et al. (2018), the IR spectroscopy method and the correlation of mechanical and spectral characteristics were used to determine the plasticity of soil materials and (Waruru et al., 2014) the IR method allowed determining a wide range of mechanical properties of clay materials including settlement and tensile characteristics.

To improve the accuracy of measuring the characteristics of soil materials, other methods based on modern physical principles have recently been developed. By Nartowska et al. (2015), Free Induction Decay (FID) method was applied to determine moisture. It was found that the correlation between the intensity of the FID signal and the mass of water reached 0.97 .

In the course of maintenance of artificial structures made of soil materials, it is necessary to take into account the changing in the plasticity index (Kwawukume et al., 2010) which may reduce the structural stability coefficient. The dynamics of changes in the mechanical properties of a structure can be studied within the framework of a monitoring system supplementing existing research methods with relatively easily implemented methods of electrical resonance measurements (Topp et al., 1982; Khakiev et al., 2012; Yavna et al., 2018).

This work's aim is to study of the possibility of determining the moisture content of soil-forming cohesive rocks at which they pass from solid to plastic state by the method of resonant electrical measurements. To this end the problem is to identify features in the behavior of the complex dielectric constant in bentonite clays and kaolin during the transition from water adsorbed on the surface of clay particles to free water in the bulk of the sample between clay particles. The solution of this problem will help to establish a correlation between mechanical and electrical soil-forming rocks based on montmorillonite and kaolinite.

\section{MATERIALS AND METHODS}

Resonator: In this work, we made a brass resonator with transverse dimensions close to the dimensions of the

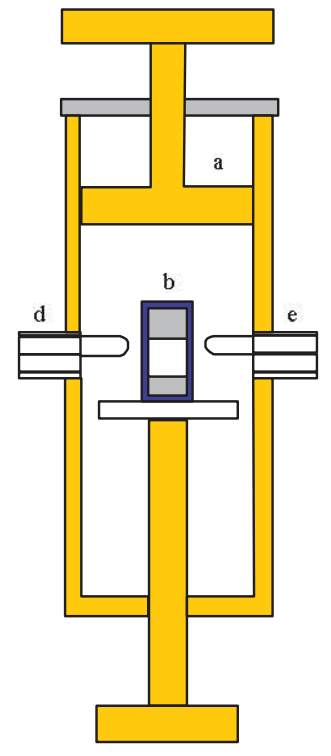

Fig. 1: Schematic representation of a resonator with a sample, a: Resonator, b: Plastic container, c: Sample, d: Port 1 and e: Port 2

cylindrical test sample with a diameter $\mathrm{d}_{0}=19.7 \mathrm{~mm}$ and a height $1-8.04 \mathrm{~mm}$. The operating frequency range in which the resonator is used is chosen to be $0.4-1.7 \mathrm{GHz}$, it coincides with the short-wavelength GPR range used to examine the structural layers of artificial structures. The most common in practice are quarter-wave resonators; this gives the resonator length $53.57 \mathrm{~mm}$ at a frequency of $1.4 \mathrm{GHz}$. The inner diameter of the resonator is determined by the size of the soil sample. The value of its outer diameter is selected from the condition that there are no waves of higher types, it amounted to $30 \mathrm{~mm}$. A sketch of the resonator with the sample container placed inside it is shown in Fig. 1.

In addition to the resonator, for experimental studies of the electrophysical properties of the samples, we used a P2M-04 transmission and reflection coefficient module operating in the frequency range of $10 \mathrm{GHz}$ and equipped with a computer with specialized software as well as a sample container (Fig. 1) made of plastic with dielectric constant 2.98. The software provides the implementation of a measurement mode selected by user, the control of measurements and display of the results.

Resonance measurement method: A theoretical study of the resonance properties of soils was carried out on the basis of computer simulation of the propagation of an electromagnetic field in a microwave cavity with samples of various materials. The computer model of the resonator cavity is created in the CST STUDIO SUITE 


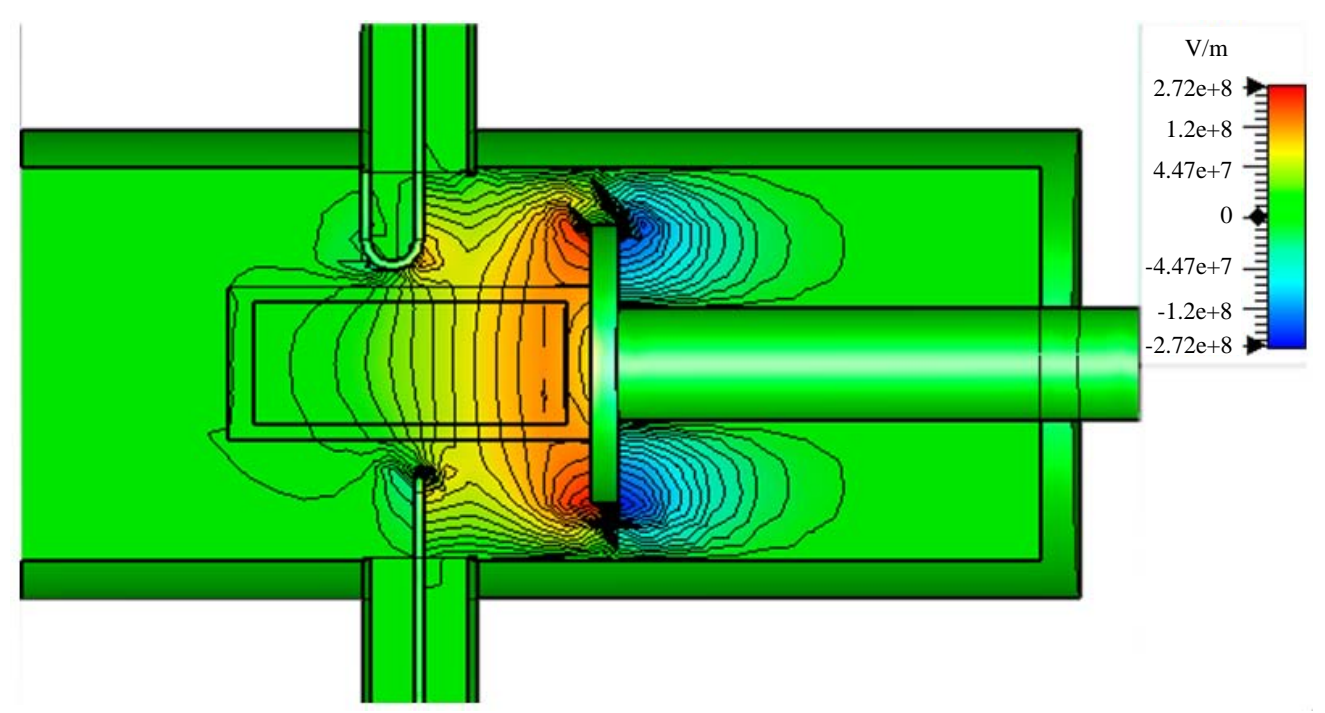

Fig. 2: Penetration of the field, sample with $\varepsilon=1$

environment. For each component of the model (Fig. 1), the geometric dimensions and electrophysical properties were set in accordance with the dimensions and properties of the prototype.

In the calculation, the finite integration method was used, implemented using the Eigenmode Solver Software unit with splitting of the space into discrete hexahedral cells. Natural frequencies and respective distributions of electromagnetic fields of systems with various electrophysical parameters are determined.

For example, in the created model for the sample with $\varepsilon=1$, the field has the maximum electric field vector $\mathrm{E}=2.72 \times 10^{8} \mathrm{~V} / \mathrm{m}$ (Fig. 2). With an increase in the dielectric constant of the sample, a field is pushed out from its volume. As the dielectric the sample constant increases, the electric field is pushed out of the sample more strongly and at $\mathrm{e}>20$, it practically does not penetrate into it.

Thus, the design of the resonator has limitations on the range of the measured permittivity of the samples which can be estimated as $\mathrm{e}<20$.

The basis for determining the value of the complex dielectric constant of the sample is a comparison of the results of direct measurements of the resonance frequency, the quality factor and the results of their computer simulation for given parameters of the dielectric constant and conductivity.

Verification of the calculation results is carried out by comparison with the results of measurements of the resonant frequencies in materials with guaranteed dielectric properties. Fluoroplastic with $\varepsilon=2.08$, polystyrene with $\varepsilon=2.6$, FLAN 2.8 with $\varepsilon=2.8$ (Fig. 1), fiberglass with $\varepsilon=6$ and FLAN 10 with $\varepsilon=10$ were used as materials placed in the container as well as their combinations.

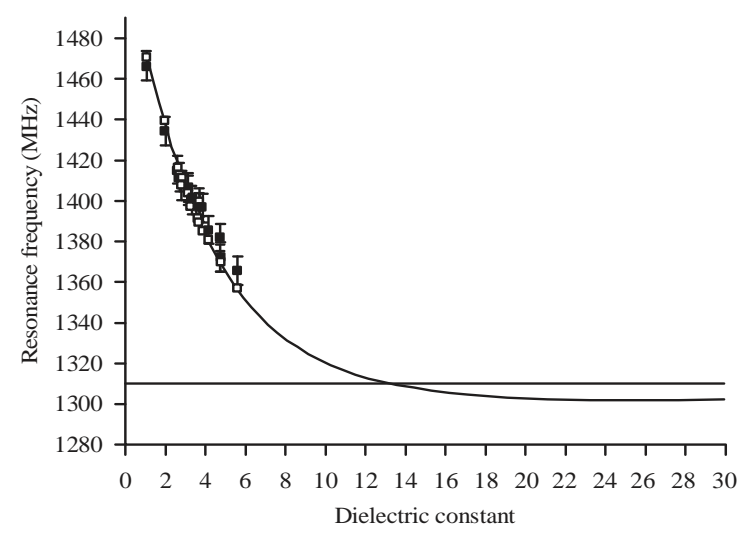

Fig. 3: The dependence of the resonance frequency on the dielectric constant of the sample. The errors of experimental measurements of $0.5 \%$ are shown

Calculated and experimental values of the resonant frequencies are compared in Fig. 3. It is seen that the accuracy of the computer model and the numerical procedure can be estimated to be $0.5 \%$ in the accessible range of the permittivity.

To determine the dielectric constant of the samples, the dependence of the resonance frequency (f) is extrapolated to the range $\mathrm{e}>6$ by the relation $\mathrm{f}=1302+217.5 \mathrm{e}^{-0.2458 \mathrm{e}}$ : the extrapolation results are shown in Fig. 3. It can be seen that for resonant frequencies less than $1310 \mathrm{MHz}$ (horizontal line in Fig. 3), the error in determining the dielectric constant increases, therefore, when processing the results of experimental measurements, this curve was used as a calibration curve to determine the dielectric constant of the samples only in the resonance frequency range ща $1300-1470 \mathrm{MHz}$. 
Sample specific conductivity during resonance measurements is determined by the equation:

$$
\sigma=\sigma_{\exp }-\sigma_{\mathrm{K}}
$$

where, $\sigma_{\exp }=\varepsilon \varepsilon_{0} \Delta \omega$ is the specific conductivity of the sample placed in the container, $\varepsilon$ is the dielectric constant of the sample is the electric constant and $\Delta \omega$ is the width of the resonance curve at half maximum, $\sigma_{\mathrm{K}}=0.92 \times 10^{-3} \mathrm{~S} / \mathrm{m}$ is the calculated specific conductivity of the resonator without a sample.

\section{RESULTS AND DISCUSSION}

The crystal structure of soil-forming clay minerals is based on silicates containing two basic structural elements: silicon-oxygen tetrahedrons and octahedra consisting of oxygen atoms or hydroxyl groups inside which aluminum, magnesium or iron atoms are located in octahedral coordination (Bergaya et al., 2006). Connecting in space through the common vertices in which oxygen atoms are located, these structural elements form two-dimensional hexagonal tetrahedral and octahedral networks. Combination of tetrahedral and octahedral grids forms two or three layer packets with a ratio of grids of types $1: 1$ and $1: 2$. Silicates have a large variety of groups and varieties which is due to their ability to isomorphic heterovalent substitutions of a part of $\mathrm{Si}^{4-}$ or $\mathrm{Al}^{3+}$ for lower valencyions (usually $\mathrm{Al}^{3+}, \mathrm{Fe}^{3+}, \mathrm{Mg}^{+}$, $\mathrm{Zn}^{2+}$ etc.). Silicates are rarely found in sedimentary rocks as single species. The studies performed by Shlykov (2000) showed that most often they are parts of a natural association that includes several fixed types of these minerals. In this work, the bentonites within the following associations are studied: Dusch (Dusch-Salakhninsky deposit, Azerbaijan Republic), Kutch (Kutch deposit, Gujarat State, India) and Zir (Zyryanovsky deposit, Russia), kaolin from Zhuravlinny Log deposit, Russia is studied as well. The main component of bentonites is montmorillonite and kaolinite is the main component of kaolin; they are studied in detail by Viani et al. (2002), Gournis et al. (2008) and Bish and Dreele (1989).

For these samples, the moisture values at the plastic limit $\left(W_{P}\right)$ were determined in a traditional way according to GOST 5180-2018 (2016) using the devices of the ASIS universal measuring complex. The measurements results are shown in Table 1.

To evaluate the accuracy of resonance measurements using the example of Dusch Bentonite in a wide range of muistures, three series of experiments were carried out to measure the dielectric constant and conductivity at different sample moisture levels. In preparation for measurements in each series, the samples of a given moisture were prepared each time from the very beginning by mixing bentonite with a given amount of distilled water. Wet samples were kept in a sealed laboratory glassware for at least $24 \mathrm{~h}$ in order to undergo consolidation processes. Before measurements, sample containers (Fig. 1) were filled with a fixed amount of a wet sample. The results of measurements of the dielectric constant and conductivity in a wide range of sample moisture are presented in Fig. 4 and 5. It can be seen from the figures that the scatter of the measured values can be estimated to be about $10 \%$.

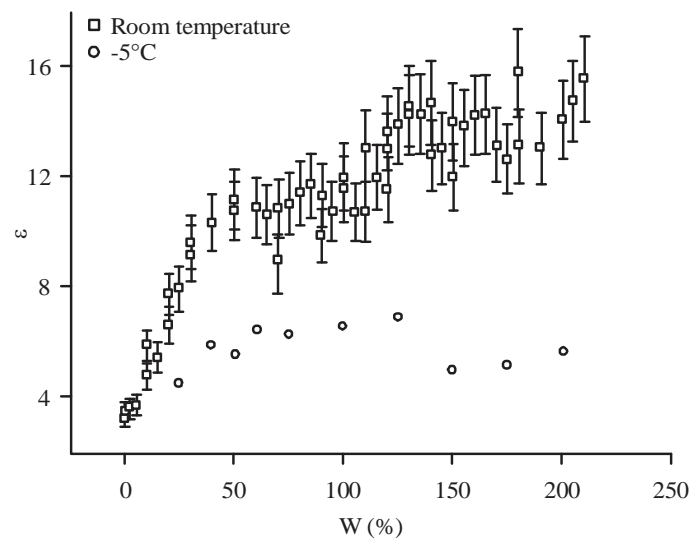

Fig. 4: Measured dielectric constant of Dusch brand bentonite, vertical bars indicate the errors of $10 \%$

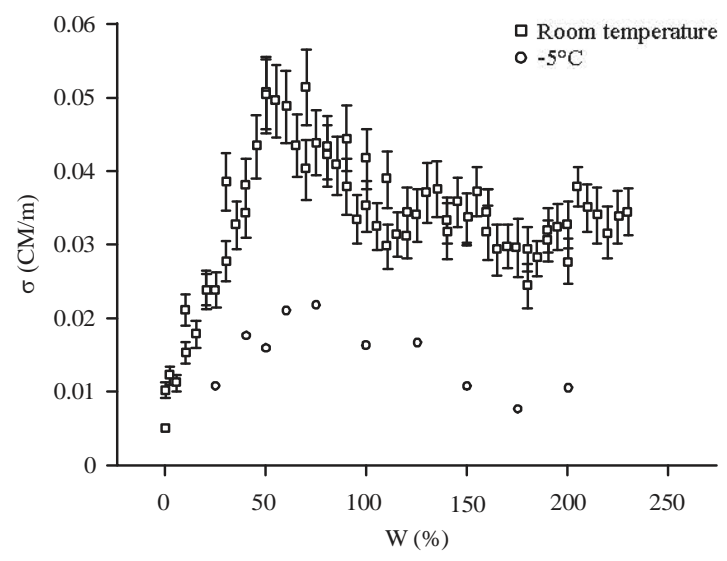

Fig. 5: Measured conductivity of Dusch brand bentonite, vertical bars indicate the errors of $10 \%$

Table 1: Moistures at the plastic limit

\begin{tabular}{lccc}
\hline Bentonite & $\begin{array}{c}\text { Moisture at } \\
\text { the plastic limit } \mathrm{W}_{\mathrm{p}}(\%)\end{array}$ & $\begin{array}{c}\text { Moisture at the plastic limit } \\
\text { determined from Fig. 6 } \mathrm{W}_{\mathrm{p}}(\%)\end{array}$ & $\begin{array}{c}\text { Moisture at the plastic limit } \\
\text { determined from Fig. } 7 \mathrm{~W}_{\mathrm{p}}(\%)\end{array}$ \\
\hline Dusch & 39.4 & 39.2 & 43.2 \\
Kutch & 47.7 & 46.8 & 54.0 \\
Zir & 35.9 & 41.6 & 38.9 \\
Kaolin & 27.4 & 22.6 & 23.8 \\
\hline
\end{tabular}




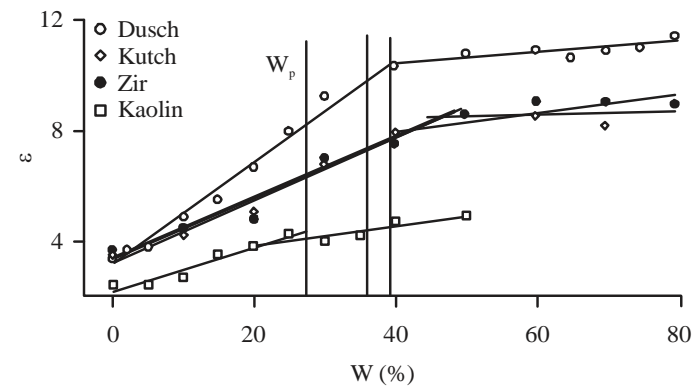

Fig. 6: Measured dielectric constants of bentonites and kaolin and a linear approximation of the experimental results; Vertical colored lines indicate the moistures at the plastic limit $\left(\mathrm{W}_{\mathrm{p}}\right)$

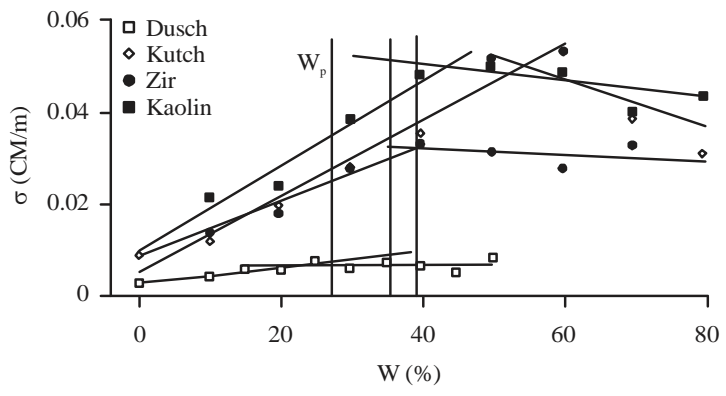

Fig. 7: Measured conductivities of bentonites and kaolin and a linear approximation of the experimental results; Vertical colored lines indicate the moistures at the plastic limit $\left(\mathrm{W}_{\mathrm{p}}\right)$

The same figures also show the electrophysical quantities measured in samples after keeping them at a temperature of $-5^{\circ} \mathrm{C}$ for $24 \mathrm{~h}$.

To quantitatively compare the electrophysical properties of bentonites and kaolin, the experimental values of their dielectric constant and conductivity are shown in Fig. 6 and 7 together with the lines indicating the moistures at the plastic limit $\left(\mathrm{W}_{\mathrm{p}}\right)$ from Table 1. The figures show that near the moisture values at the plastic limit, the steepness of the graphs of the measured electrophysical quantities changes. In this regard, the experimental values are approximated by linear dependences in the moisture ranges below and above the points of the slope steepness change. The approximation results are shown in Fig. 6 and 7.

As noted above, the accuracy of the resonance measurements in Fig. 5 and 6 is estimated to be $10 \%$. With this accuracy, the dependences of the Dusch bentonite dielectric constant in the moisture intervals separated by the moisture value at the plastic limit (39.4\%, Table 1) can be considered linear. At that, at high moistures above the plastic limit the approximating line makes a smaller angle with the axis of moistures than at small ones under the plastic limit. When analyzing the results obtained, it should be taken into account that the increase in moisture above the plastic limit is accompanied by swelling of bentonite. Resultingly, the fraction of clay particles decreases in a fixed volume of the sample and the portion of unbound water increases linearly; this causes a linear increase in the dielectric constant of the sample.

An increase in the moisture content of the Dusch brand bentonite samples in the range limited by the plastic limit leads to an increase in conductivity as shown in Fig. 6. This increase of the conductivity can be considered linear. Further increase in moisture is accompanied by the decrease in the number of ions in the sample; this leads to the decrease in conductivity with a tendency to saturation. However, along with this, in a small interval of moisture above the plastic limit, a linear approximation can be used (Fig. 6 and 7). The moisture values at the intersection points of the approximating straight lines assigned as moistures at the plastic limits are shown in Table 1. The results presented in the table allow one to conclude that the deviations of the data determined by the method of resonance measurements of dielectric constant and conductivity as well as the deviations of their average value from the values determined by the traditional method are of the order of $10 \%$. At the same time, the statistical processing of the results of a series of measurements of moisture at the plastic limit made by traditional method has the accuracy of $5-10 \%$ which makes the resonance measurement method competitive in accuracy.

The data shown in Fig. 6 and 7 make it possible to compare the dielectric constants of bentonites and kaolin. It can be seen that at same moistures, the dielectric constant of bentonites in reported moisture range is 1.5-2 and the conductivity is $4-5$ times greater than those of kaolin. This circumstance explains limited applicab ility of the method of microwave sounding methods in low-resistance clays in a natural moisture state.

The interaction of water and ice in the presence of clay minerals has been studied by Murray et al. (2011) and Wang and Schmugge (1980). By Murray et al. (2011), conditions were studied under which the kaolinite mineral immersed in water leads to its crystallization. A simple empirical model was proposed by Wang and Schmugge (1980) to describe the dielectric properties of soil-water mixtures. With its help, the dielectric constants of mixtures were calculated and it has been shown that their values were in reasonable agreement with the results of measurements in a wide range of moisture.

In this work, we studied the change in the electrophysical characteristics of the Dusch brand bentonite during freezing. For this purpose, the samples were kept for $72 \mathrm{~h}$ at a temperature of $-5^{\circ} \mathrm{C}$. The measurements results are shown in Fig. 4 and 5. 
Figure 4 shows that when the sample is frozen, the dielectric constant decreases over the entire range of moisture considered. This behavior can be explained by the formation of ice inclusions, the dielectric constant of which in the microwave range is noticeably lower than that of water and according to Kulizhnikov and Fedorov (2015) and Matsumoto et al. (2019) is 3-4.

Formation of ice in a bentonite sample leads to a decrease in the number of water molecules adsorbed on the surface of clay particles. When the sample moisture is at the plastic limit, when all water molecules are on the surface of clay particles, the dielectric constant is $10 \pm 1$ (Fig. 4). When a sample is frozen in this state, the dielectric constant decreases by a factor of 2 which can be explained by departure of a half of the water molecules adsorbed by clay particles into the ice particles the dielectric constant of which is slightly less than the dielectric constant of dry bentonite.

It is seen from Fig. 4 that at moistures exceeding the plastic limit of bentonite $(39.4 \%$, Table 1) at room temperature, an increase in dielectric constant is observed with increasing moisture. When samples are frozen in this moisture range, the increase in dielectric constant is replaced by the decrease. In interpreting this behavior, it is necessary to take into account the fact that the samples have a constant volume and with the increase in moisture, the contribution of clay particles decreases while that of water, increases. With the formation of ice, the dielectric constant of the samples decreases as the dielectric constant of water is less than that of frozen samples with moisture at the plastic limit $(5.0 \pm 0.5$, Fig. 4). In the limit of high moisture, the value of the dielectric constant of the samples should tend to the value of that of water, in the range of 3-4 (Kulizhnikov and Fedorov, 2015; Matsumoto et al., 2019).

\section{CONCLUSION}

At low temperatures, the conductivity of the Dusch bentonite samples decreases to the values typical of dry bentonite. This circumstance can be explained by the decrease in the mobility of ions at negative temperatures and the decrease in the number of water molecules adsorbed on the surface of clay particles.

\section{ACKNOWLEDGEMENTS}

This study was supported by the Federal Agency for Railway Transport in 2019 (Clause 3 of Protocol No. VCh-57 of December 25, 2018).

\section{REFERENCES}

ASTMD4318-10, 2010. Standard test methods for liquid limit, plastic limit and plasticity index of soils. ASTM International, West Conshohocken, Pennsylvania. https://www.astm.org/DATABASE.CART/HISTO RICAL/D4318-10.htm

Andrade, F.A., H.A. Al-Qureshi and D. Hotza, 2011. Measuring the plasticity of clays: A review. Applied Clay Sci., Vol. 51, 10.1016/j.clay.2010.10.028

Bergaya, F., B. Theng and G. Lagary, 2006. Handbook of Clay Science. 1st Edn., Elsevier, Amesterdam, ISBN-13: 978-0080441832.

Bish, D.L. and R.B.V. Dreele, 1989. Rietveld refinement of non- hydrogen atomic positions in kaolinite. Clays Clay Miner., 37: 289-296.

GOST 5180-2015, 2016. [Soils, laboratory methods for determination of physical characteristics]. Standardinform, Moscow, Russia. (In Russian) https://translate.google. $\mathrm{com} /$ translate $\mathrm{hl}=\mathrm{en} \& \mathrm{sl}=\mathrm{ru}$ $\& u=h t t p s: / / f i l e s . s t r o y i n f . r u / I n d e x 2 / 1 / 4293758 / 4293$ 758554.htm \&prev = search

Gournis, D., A. Lappas, M.A. Karakassides, D. Tobbens and A. Moukarika, 2008. A neutron diffraction study of alkali cation migration in montmorillonites. Phys. Chem. Miner., 35: 49-58.

He, M.C., J. Zhao and S.X. Wang, 2013. Adsorption and diffusion of $\mathrm{Pb}$ (II) on the kaolinite(001) surface: $\mathrm{A}$ density-functional theory study. Applied Clay Sci., 85: 74-79.

$\mathrm{Hu}$, X.L. and A. Michaelides, 2007. Ice formation on kaolinite: Lattice match or amphoterism? Surf. Sci., 601: 5378-5381.

ISO/TS 17892-12, 2004. Geotechnical investigation and testing- laboratory testing of soil-part 12 : Determination of atterberg limits. ISO, Geneva, Switzerland. https://www.iso.org/standard/ 38525.html

Kasprzhitskii, A., G. Lazorenko, A. Khater and V. Yavna, 2018. Mid- infrared spectroscopic assessment of plasticity characteristics of clay soils. Miner., Vol. 8, No. 5. 10.3390/min 8050184

Khakiev, Z., K. Kislitsa and V. Yavna, 2012. Efficiency evaluation of ground-penetrating radar by the results of measurement of dielectric properties of soils. J. Applied Phys., Vol. 112, No. 12. 10.1063/1.4770470

Kodicherla, S.P.K. and D.K. Nandyala, 2016. Use of CPT and DCP based correlations in characterization of subgrade of a highway in Southern Ethiopia Region. Int. J. Geo Eng., Vol. 7, 10.1186/s40703-016-0025-8

Kulizhnikov, A.M. and M.P. Fedorov, 2015. Empirical and experimental graund penetrating radar works on ice bridges. Roads Bridges, 2: 165-184. 
Kwawukume, P.S., A. Essuman and R. Amoanyi, 2010. Measurement and enhancement of plasticity indices of some extruded Ghanaian clays. J. Ghana Sci. Assoc., Vol. 12, No. 2. 10.4314/jgsa.v12i2.62803

Liu, X., X. Lu, R. Wang, E.J. Meijer, H. Zhou and H. He, 2012. Atomic scale structures of interfaces between kaolinite edges and water. Geochim. Cosmochim. Acta, 92: 233-242.

Matsumoto, M., M. Yoshimura, K. Naoki, K. Cho and H. Wakabayashi, 2019. Ground penetrating radar data interpretation using electromagnetic field analysis for sea ice thickness measurement. Int. Arch. Photogramm. Remote Sens. Spatial Inf. Sci., 42: 47-50.

Modesto, C.D.O. and A.M. Bernardin, 2008. Determination of clay plasticity: Indentation method versus Pfefferkorn method. Applied Clay Sci., 40: 15-19.

Murray, B.J., S.L. Broadley, T.W. Wilson, J.D. Atkinson and R.H. Wills, 2011. Heterogeneous freezing of water droplets containing kaolinite particles. Atmos. Chem. Phys., 11: 4191-4207.

Nartowska, E., T. Kozlowski and M. Kolankowska, 2015. Application of $1 \mathrm{H}-\mathrm{NMR}$ relaxometry to the determination of the water content in clay soils. Struct. Environ., 7: 189-193.

Ortega-Castro, J., N. Hernandez-Haro, D. MunozSantiburcio, A. Hernandez-Laguna and C.I.SainzDiaz, 2009. Crystal structure and hydroxyl group vibrational frequencies of phyllosilicates by DFT methods. J. Mol. Struct. THEOCHEM, 912: 82-87.

Scholtzova, E., D. Tunega, J. Madejova, H. Palkova and P. Komadel, 2013. Theoretical and experimental study of montmorillonite intercalated with tetramethylammonium cation. Vib. Spectrosc., 66: 123-131.

Shlykov, V.G., 2000. Using the structural characteristics of clay minerals to assess the physicochemical properties of dispersed soils. Geoecology, 1: 43-52.

Solc, R., M.H. Gerzabek, H. Lischka and D. Tunega, 2011. Wettability of kaolinite (001) surfacesmolecular dynamic study. Geoderma, 169: 47-54.

Timon, V., C.S. Praveen, E. Escamilla-Roa and M. Valant, 2013. Hybrid density functional based study on the band structure of trioctahedral mica and its dependence on the variation of $\mathrm{Fe}^{2+}$ content. J. Mol. Graphics Modell., 44: 129-135.
Topp, G.C., J.L. Davis and A.P. Annan, 1982. Electromagnetic determination of soil water content using TDR: I. applications to wetting fronts and steep gradients1. Soil Sci. Soc. Am. J., 46: 672-678.

Verma, S.K. and S. Maru, 2013. Behaviourial study of expansive soils and its effect on structures-A review. Int. J. Innovations Eng. Technol., 2: 228-238.

Viani, A., A.F. Gualtieri and G. Artioli, 2002. The nature of disorder In montmorillonite by simulation of X-ray powder patterns. Am. Mineral., 87: 966-975.

Vlcek, J., T. Vondrackova, J. Plachy, V. Nyvlt and D. Kucerka, 2016. Comparative analysis of dynamic methods for earthwork controlling. Procedia Eng., 161: 483-488.

Wang, J.R. and T.J. Schmugge, 1980. An empirical model for the complex dielectric permittivity of soils as a function of water content. IEEE Trans. Geosci. Remote Sens., 18: 288-295.

Waruru, B.K., K.D. Shepherd, G.M. Ndegwa, P.T. Kamoni and A.M. Sila, 2014. Rapid estimation of soil engineering properties using diffuse reflectance near infrared spectroscopy. Biosyst. Eng., 121: 177-185.

Wungu, T.D.K., F. Rusydi, H.K. Dipojono and H. Kasai, 2012. A density functional theory study on the origin of lithium- montmorillonite's conductivity at low water content: A first investigation. Solid State Commun., 152: 1862-1866.

Yavna, V., Z. Khakiev, G. Lazorenko, A. Kasprzhitskii and S. Sulavko, 2018. Quantitative GPR inspection of quasi-homogeneous ground layers. MATEC. Web Conferences, Vol. 251, 10.1051/matecconf/ 201825102025

Zhang, C., Y.H. Qi, P. Qian, M.J. Zhong, L. Wang and H.Z. Yin, 2014. Quantum chemical study of the adsorption of water molecules on kaolinite surfaces. Comput. Theor. Chem., 1046: 10-19.

Zornberg, J.G., J.A. Kuhn and M.D. Plaisted, 2008. Characterization of the swelling properties of highly plastic clays using centrifuge technology. CTR Technical Report: 0-6048-1, Center for Transportation Research, UT Austin, Austin, Texas. http://citeseerx.ist.psu.edu/viewdoc/download?doi= 10.1.1.215.343\&rep $=$ rep1\&type $=$ pdf 